Dr. Leonard Stewart said, that we must be guided in our treatment of mania by the physical symptoms. He related a case to show that in mania, attended with much physical debility, tonics and even stimulants were necessary; but that after the lapse of a few munths, when the health and strength of the patient became restored, small and repeated blood-lettings were resorted to with great advantage.

Mr. Proctor cantioned young practitioners against measuring the necessity of blood-letting by the degree of mental excitement present, for irritation of brain might exist with a state opposed to that of inflammation.

Mr. Clifton remarked, that mania might be accidentally complicated with inflammation of the brain, but that inflammation was by no means necessarily present. He inquired the experience of members regarding the moral treatment of insanity, and instanced the astonishing results of Dr. Conolly's non-restraint practice at Hanwell. The humane system had gained attention among the public, the profession would do well to inquire fully into the subject.

Mr. Headland said, that he agreed with Cullen in placing mania under the class neuroses, order adynamia, and that consequently he did not think it an inflammatory disorder. If inflammation did exist, it was only as a consequence of the disordered condition of the mind. He thought it quite inconsistent with our observations on insanity to consider it as Mr. Solly did, always associated with inflammation of the brain; for were this the case, anti-inflammatory remedies would always be of service : whereas, we knew, on the contrary, that they were often followed by an aggravation of the symptoms. The more rational treatment of insanity was that which brought into useful action those faculties of the mind which remained healthy. To arrive at a proper mode of treatment in each case, we must be acquainted with the previous history of the patient. Whatever, however, was the cause of mania, sleep, if it could be procured, was always of advantage, and would do much towards the restoration of the health of the patient. The sooner this sleep could be procured the better. The preparations of opium for this purpose, might be exhibited at any stage of the disorder, where the tongue was not dry or loaded; and where it gave evidence of anything like tremor, or where there was tremor of the body generally, and moisture of the skin. Under these circumstances, whatever the state of the pulse, opium might be safely and advantageously employed.

Mr. Dendy believed that the original cause of mania was a metaphysical one, but that in all cases there was an abnormal condition of the brain present, but which was not necessarily inflammatory.
In regard to the non-restraint system, $\mathrm{Mr}_{\mathrm{r}}$. Dramond and Mr. Elliotr contended that there were some cases of mania in which restraint could not safely be dispensed with ; such were cases in which patients eat their own freces, or had a predisposition to suicide.

Mr. Clarke remarked, that a fortnight ago, in Bethlem, where, some time since, it was said that restraint could not be dispensed with, there was not one patient out of three hundred and sixty under restraint! The last reports of the Gloucestershire, the Edinburgh, and other asylums, showed that the system of Dr. Conolly was as practicable as it was humane.

Mr. Clifton said, if the treatment pur. sued by Dr. Conolly in the Hanwell Asylum was found to answer, would the better classes of society submit, in private asylums, to that restraint which was dispensed with in the cases of their poorer brethren in public institutions?

Mr. Pilcher had been interested with the discussion which had occupied the society during the last three evenings. The difference of opinion was more imaginary than real. $\mathrm{He}$ proceeded to say that he considered mania was essentially a physical disease, and that it was situated in the grey matter of the brain. He referred to phreno$\operatorname{logy}$, and thought that it threw more light on insanity than any of the other systems which had been promulgated.

This being the last meeting of the session, the society adjourned until September 26th.

\section{PHRENOLOGY AND PHRENOLOGISTS.}

\section{To the Editor of THE LANCET.}

SIR,-The letters of your correspondents "Spectator" and "W. H. Brooks" in your Number of Saturday last provoke a few remarks, for which $I$ have to crave the indulgence of a place in your columns. I must beg to remind those gentlemen, and your readers generally, that up to this time the facts brought forward in Mr. Sampson's letters remain uncontradicted, and the arguments unrefuted; and $I$ cannot help thinking that Mr. Sampson's opponents would do greater service to science and to themselves if they would investigate the truth of his conclusions, instead of indulging in vain speculations as to the consequences which those conclusions may involve. Whether the views in question be "most dangerous" as in a former letter your correspondent "Spectator" affirms, or whether they favour " the untenable positions of fatalism" as $\mathbf{M r}$. Rrooks seems to imagine, are questions be. side the real one. Are they true or false? If they are true, it is idle to talk of their being "dangerous ;" truth can only be dangerous to error. If they are false, let it be shown where the fallacy lies-let it be 
pointed out fairly, and in precise unequivocal terms. The proposition, consciously or unconsciously affirmed by "Spectator" in his last letter-the proposition which he helps to establish by his quotation from Hazlitt, viz., that beings are to be considered "moral and accountable" in the ratio of their susceptibility to " moral motives," is one to the truth of which Mr. Sampson will, no doubt, cheerfully assent. The question still remains open, viz., Are all men equally susceptible to the influence of moral motives? I pass by your correspondent's statement regarding "the proper province of phrenology," being utterly at a loss to reconcile it with even a moderate knowledge on his part of the elementary principles of the science in which he professes to put faith. Phreno$\operatorname{logy}$, as explained by Gall, Spurzheim, Combe, and others, teaches us, 1st, that the brain is the organ of the mind; 2nd, that the brain is a congeries of organs; 3rd, that, cateris paribus, size is the measure of power; Ath, that susceptibility and activity depend upon the temperament, the influence of which extends alike to all the cerebral organs. Phrenology teaches us, that men with heads like Melancthon, experience lively emotions of a moral character, and that such men feel strongly impelled to do that which is right. That men with heads like Hare or Burke may recognise intellectually the difference between right and wrong; that is, they may perceive that a particular action is of a class called wrong by the world, that another is of a class called right by the world; but that the sensible appreciation of the morality of the act, the feeling or sentiment which can alone furnish a restraining motive, is in them extremely weak, and liable to be overborne by strong temptation. The question evidently suggested to Mr. Sampson's mind by this doctrine, is not-What is then the degree of such a man's moral guilt in the sight of his Maker? Such a question would be at once impious and absurd. None but the "Searcher of all hearts" himself can determine what is due from each of his creatures to $\mathrm{Mim}$; but rather this, 'To what extent are we on earth justified in taking vengeance upon our fellow-man for "crimes" committed by him? Mr. Sampson may be right, or he may be wrong: one thing is clear, he is in possession of the field of action; and so he is likely to remain, until " a stronger than he" shall overcome him with the weapons of fact and argument which he employs so ably. I am, Sir, your faithful servant,

R. W. Heurthey.

萿ensington, May 30, 1842.

\section{NOTE FROM DR. DICK.}

To the Editor of The Lancet.

SIR,-I must make a thousand apologies to you and your readers, for returning once more to that question of phrenology, vexata
(I may surely well add) usque ad nauseam; but justice to myself requires me to state, explicitly and once for all, that (contrary to what "Spectator" supposes) I am a phrenologist! I believe, and in my late papers have repeatedly asserted, the brain to be the organ of the mind; which opinion or admis. sion regularly constitutes me a phrenologist. It is true, indeed, that my phrenological creed (sceptic as I must appear to the orthodox Messrs. Sampson and Combe!) consists of but a single, and that, too, a most general doctrine; yet for going beyond which I de. liberately maintain we have no data. That single doctrine, which I purposely clothe in the most general terms possible, is, that there seems to exist a relation between the anterior part of the brain and the intellect. What I consider the amazing credulity of Messis. Combe, Sampson, \&c., a credulity which partly surprises, partly amuses me, will by no means prevent me from avowing myself a phrenologist in my way, which it will be perceived is widely different from, though as real as theirs. I may add my firm and solemn conviction, that until it be generally understood, as it long since ought to have been, that sound and rational phrenolooy and Mr. Combe's theories, are things just as opposite as light and night, an eternal hos. tility will ex ist to the former, in many or in most intelligent minds.

Another grand tenet of mine, of which I hope and believe most of your readers are convinced, is, that so long as a man is intellectually sane he is morally responsible. The utopian (or not to misapply a word of pleas. ing import) the wildly chimerical character of the contrary view, will ever be a safe antidote to the dangerousness of it. I am, $\mathrm{Bir}$, your obedient servant,

London, May, 1842.

Robert Dick, M.D.

\section{MEDICAL ASSOCIATIONS} FOR THE

\section{PREVENTION OF ILLEGAL PRACTICE.}

\section{To the Editor of THE LANCET.}

Sir,-I beg leave, through the medium of your widely-circulated $\mathbf{J}$ oumal, to call upon the legally-authorised practitioners of medicine in this metropolis to form district as50. ciations for the suppression of illegal practice. It is notorious that such is carried on to an enormous extent; but under the influ. ence of the feeling that what is the business of everybody is the business of nobodr, nothing is done: some cases, few and far between, are exposed, but the great mass of the evil is allowed to exist undisturbed. It is certainly by no means a pleasant thing for an individual to appear as an informer, but the odium would not be thus felt if the matter 